\title{
COVID-19 Y LA EPIDEMIA PERMANENTE EN MÉXICO: LA VIOLENCIA CONTRA LAS MUJERES
}

\section{COVID-19 E A EPIDEMIA PERMANENTE NO MÉXICO: VIOLÊNCIA CONTRA AS MULHERES}

COVID-19 AND THE PERMANENT EPIDEMIC IN MEXICO: VIOLENCE AGAINST WOMEN

\author{
Alma Rosa Sánchez Olvera * \\ almarosan59@gmail.com
}

RESUMEN: En este artículo, mostramos datos que en la sociedad mexicana ilustran la magnitud de la violencia contra las mujeres, en el contexto de la pandemia Covid-19. A partir de la perspectiva de los estudios críticos de género feministas, interpretamos la fuerza sociopolítica que ha adquirido el movimiento feminista encabezado por las jóvenes, como uno de los movimientos sociales más desafiantes, críticos y transgresores a la cultura patriarcal, misógina y sexista, el movimiento se ha constituido en un sujeto político transgresor y propositivo para la vida digna y no violenta de las mujeres.

Palabras Clave: Covid-19, Violencia contra mujeres, Movimiento social feminista.

RESUMO: Neste artigo, apresentamos dados que na sociedade mexicana ilustram a magnitude da violência contra as mulheres, no contexto da pandemia de Covid-19. Na perspectiva dos estudos feministas críticos de gênero, interpretamos a força sociopolítica que o movimento feminista liderado por mulheres jovens adquiriu, como um dos movimentos sociais mais desafiadores, críticos e transgressores da cultura patriarcal, misógino e sexista, o movimento tornou-se um Sujeito político transgressivo e pró-ativo por uma vida digna e não violenta para as mulheres.

PalAVRAS-ChAVE: Covid-19, Violência contra mulheres, Movimento social feminista.

ABSTRACT: In this article, we show data that illustrates the magnitude of violence against women in the context of the Covid-19 pandemic in Mexican society. From the perspective of critical feminist gender studies, we interpret the sociopolitical strength that the feminist movement headed by young women has acquired, as one of the most challenging, critical and transgressive social movements with regards to patriarcal, misoginistic and sexist culture. The feminist movement has been constituted as a transgressive and propositive political subject for the dignified and non violent life of women.

KEYWORDS: Covid-19, Violence against women, Social feminist movement.

Covid-19 y la epidemia permanente en México: la violencia contra las mujeres

Las aristas para entender y explicar la pandemia mundial son múltiples y diversas, en este texto destacamos algunas reflexiones contextuales que nos parece preciso señalar: el recrudecimiento de las desigualdades sociales, el dominio del capitalismo digital, la discriminación al personal de salud. No obstante, en esta exposición solo profundizaremos en la pandemia que se ha agudizado en las vidas y los cuerpos de cientos de mujeres, la violencia contra las mujeres.

Nuestro objetivo es reflexionar a partir los estudios críticos de género, la magnitud de la violencia contra las mujeres en México, problemática social, legal y política que en el

\footnotetext{
* Doctora en Sociología por la Facultad de Ciencias Políticas y Sociales de la Universidad Nacional Autónoma de México.
} 
contexto de la Covid-19 se ha agudizado y frente a la omisión del gobierno, el quehacer de la sociedad civil de mujeres feministas ha cobrado especial relevancia en la atención y acompañamiento para las víctimas de violencia.

\section{El contexto}

Covid y la desigualdad social

La pandemia causada por el nuevo coronavirus SARS-CoV-2 (covid-19) ha recorrido todo el planeta y obligado a encerrarse en sus hogares a miles de millones de personas. En poco tiempo, ha provocado una auténtica crisis sistémica y sembrado la duda, sobre el sentido mismo de la civilización humana. La Covid, nos ha mostrado que es una pandemia que no discrimina en razón del sexo, color de piel, religión, clase social, ataca a todos por igual. Sin embargo, mundialmente podemos observar que los más expuestos son los grupos sociales de trabajadores, los empleados de la industria de la construcción, el personal de salud, los transportistas, las afanadoras de los hospitales, las trabajadoras del servicio doméstico, los repartidores de mercancías, los empleados en tiendas de autoservicios, los países dependen de esos trabajadores para el funcionamiento de la economía.

La Covid, ataca con mayor contundencia a los más pobres de nuestro país, el encierro de las familias se acompaña de hacinamiento, falta de alimentos, carencia de servicios, lavarse las manos, es una proeza en territorios urbanos, cinturones de miseria que carecen de agua corriente. Hoy sabemos que la pandemia no es solo la expresión de una crisis sanitaria, a diez meses de encierro, se ha evidenciado una convulsión en las relaciones humanas, las instituciones y el sistema económico de México y del mundo.

La pandemia ha sacudido a un mundo que ya era profundamente desigual. En todos los países del planeta, uno tras otro, el virus ha magnificado y agravado las desigualdades ya existentes. Cualquiera puede contagiarse, es el único aspecto igualitario de esta pandemia. Las personas en mayor situación de pobreza tienen menos posibilidades de aislarse y de protegerse a sí mismas; también es más probable que ya tuviesen problemas de salud previos, lo cual incrementa a su vez sus posibilidades de morir a causa del virus. A nivel económico, decenas de millones de personas están perdiendo su empleo, lo cual se traduce en hambre y graves dificultades para sobrevivir. Por su parte, las mujeres constituyen la inmensa mayoría 
del personal de salud, y son una población especialmente afectada. En la mayoría de los países, las personas negras y pertenecientes a minorías étnicas tienen muchas más probabilidades de morir de COVID-19 que las personas blancas (OXFAM, 2020).

\section{El dominio de las tecnologías en el mundo de vida: capitalismo digital}

Las aplicaciones digitales, el uso de las plataformas, la comunicación virtual se ha impuesto en la vida cotidiana, familiar, institucional, laboral. Sin embargo, la Covid ha puesto de manifiesto las profundas desigualdades que existen en nuestra sociedad respecto al acceso y habilidades en el manejo de las tecnologías; las brechas digitales han mostrado su lado amargo, la falta de equipo, conexión, habilidades, inexperiencia, hacen evidente el analfabetismo digital, con tales carencias cientos de familias mexicanas, se han convertido en escuelas virtuales que orientan la formación escolar de la niñez mexicana. Paradójicamente, a lo que afirma Byun (2016) este derroche de tecnologías futuristas no ha resultado suficiente y definitivo para combatir la expansión de la Covid-19. Ni siquiera en Corea del Sur, China, Taiwán, Hong Kong, Vietnam o Singapur... (50 La Vanguardia, Barcelona, 2 de abril de 2020)

Los héroes de nuestro tiempo

En Europa, han sido los médicos, las enfermeras, el personal auxiliar y otros trabajadores de la salud convertidos en protagonistas involuntarios, conquistando elogios y aplausos desde los balcones, las plazas y las calles de ciudades de todo el mundo. Son funcionarios públicos, para quienes la salud de la población no es una mercancía sino una necesidad básica, un derecho humano. Ramonet (25 abril 2020).

¿Y en México, el personal de salud, es apreciado por su heroísmo? La epidemia mundial, ha puesto de manifiesto las profundas desigualdades de acceso a la salud, falta de recursos materiales y humanos, en nuestro país no solo adolecemos de los insumos pertinentes para enfrentar la epidemia, sino además del personal médico capacitado que le haga frente. Es paradójico, año tras año los médicos que desean hacer una especialidad en el sistema de salud, se enfrentan a un riguroso examen nacional de residencia y durante los últimos 15 años solo han sido aceptados el 10 por ciento del total de aquellos que lo aplican anualmente. Si no hay especialistas, es porque el propio sistema de salud los ha expulsado. 
Aún más, la Covid-19 ha puesto de manifiesto el dominio del sentido común, en el imaginario de muchos mexicanos, su visión anticientífica ha dado muestras de agresión, maltrato y discriminación aquellos que portan el uniforme blanco. ¿A que nos convoca esta situación? ¿Es solo un asunto de ignorancia, o es que el pensamiento mágico sigue dominando más, de lo que creemos en nuestro pueblo?

La permanente epidemia en México: la violencia contra las mujeres

Un hecho social indiscutible, es el predominio de la violencia sexual y familiar contra las mujeres en tiempos de Covid. En el 2020 fueron asesinadas 2,874 mujeres y niñas, solo un $26 \%$ (724) casos se están investigando como feminicidio; los estados con mayor número de asesinatos de mujeres: Guanajuato, Chihuahua, Estado de México, Baja California, Michoacán y Guerrero; Al menos en 12 estados de la República de enero a agosto desaparecieron 5,223, mujeres y niñas, 1,223 están pendientes de localizar; y en el periodo de enero- octubre 2020 se han denunciado 13,867 violaciones sexuales (Observatorio Ciudadano Nacional del Feminicidio, 25 de noviembre 2020).

Covid y violencia contra las mujeres; una mirada desde los estudios críticos de género

Frente a la pandemia que domina en los cuerpos y las vidas de las mujeres en México, vale la pena destacar en esta exposición, uno de los escenarios más indignantes y violatorios de los derechos humanos, la violencia contra las mujeres.

Las violencias que viven las niñas, adolescentes y mujeres en México son una
de las manifestaciones más extremas y alarmantes de la situación de de-
sigualdad estructural, de discriminación y de negación de derechos, presente
en los distintos ámbitos en donde se desarrolla su vida, a pesar de los avances
jurídicos e institucionales desarrollados en los últimos 10 años (ONU MUJE-
RES, 2020).

Nuestra mirada, se apoya en los aportes que los estudios críticos de género, nos ofrecen para explicar, comprender y deconstruir las desigualdades, el predominio de relaciones de poder de los hombres sobre las mujeres. En concordancia con Patricia Castañeda (2008), la investigación feminista, es socialmente relevante para las mujeres y para toda la humanidad, aporta elementos sustantivos de transformación social centrados en la erradicación de todas las formas de opresión, empezando por el género; es experiencial en tanto las experiencias vitales se encuentran significadas por el poder; recupera la voz de las propias mujeres; es 
comprometida pues propone acciones afirmativas que devengan en políticas públicas y derechos humanos que fortalezcan la ciudadanía de las mujeres y los hombres; es contextual, en tanto refiere a una investigación situada; es multimetodológica, comprende una diversidad en los procedimientos de investigación que generalmente se acompañan de metodologías mixtas, teoría de género y perspectiva de género feminista.

Con ese lente, perspectiva de género feminista, explicaremos las violencias contra las mujeres en tiempos de Covid-19 en la sociedad mexicana.

Violencia contra las mujeres es diferente a violencia de género en el año 1994, la Asamblea General de las Naciones Unidas, en el artículo $1^{\circ}$ de la "Declaración sobre la Eliminación de la Violencia contra la Mujer", la define como:

Todo acto de violencia basado en la pertenencia al sexo femenino que pueda tener como resultado un daño o sufrimiento físico, sexual o psicológico para la mujer, así como las amenazas de tales actos, la coerción o la privación arbitraria de la libertad, tanto si se producen en la vida pública como en la vida privada" los tipos de violencia contra las mujeres más recurrentes son violencia sexual, violencia psicológica, violencia doméstica.

Por su parte, la violencia de género, se entiende como: la expresión de relaciones desiguales de poder entre hombres y mujeres, bajo un orden de dominación masculina, se comprende con mayor claridad porque una abrumadora mayoría de personas violentadas son mujeres, niñas y niños. Por esta razón, a veces se utiliza el término "violencia de género" como un sinónimo de violencia en contra las mujeres. Sin embargo, la afirmación anterior no implica el desconocimiento o la negación de que también existen expresiones de violencia de género ejercidas contra y entre hombres; por ejemplo, las que afectan a los homosexuales y transgénero, o el abuso infantil hacia hombres menores. Al respecto, cabe agregar que la violencia de género contra los hombres es ejercida también mayoritariamente por hombres, y es producto del modelo de masculinidad autoritario y dominador hacia mujeres y menores, que se siente cuestionado ante otros modelos de masculinidad u otras opciones sexuales. En este orden de ideas, las violencias ${ }^{1}$ que se mencionaran en este artículo son las que cobran expresión en la violencia contra las mujeres.

\footnotetext{
${ }^{1}$ La Ley General de Acceso a una Vida libre de Violencia (2007) precisa con claridad los tipos y modalidades de violencia contra la mujer. En el primer caso destaca: la psicoemocional que puede consistir en abandono descuido reiterado, celotipia, insultos, devaluación infidelidad, marginación, indiferencia, comparaciones destructivas, rechazo, las cuales conllevan a la víctima a la depresión, aislamiento, devaluación de su autoestima o incluso
} 
Con la llamada gubernamental, "quédate en casa" como una forma de contención para la propagación de la pandemia, la violencia familiar en los hogares mexicanos y de otros países (España, Estados Unidos, Colombia, Brasil) se incrementó.

La Violencia familiar es multicausal, es preciso entenderla como un continuo de violencias (verbal, psicológica, sexual, patrimonial) y al mismo tiempo entenderla como un entramado de factores sociales, normativos, morales y de poder que se enmarcan en la cultura patriarcal².

El Artículo 7 de la Ley General de Acceso a una Vida Libre de Violencia (2007) establece que la Violencia familiar es:

Es el acto abusivo de poder u omisión intencional, dirigido a dominar, someter, controlar o agredir de manera física, verbal o psicológica, patrimonial económica, sexual a las mujeres, dentro o fuera del domicilio familiar, cuyo agresor tenga o haya tenido relación de parentesco por consanguinidad o afinidad de matrimonio, concubinato o mantengan o hayan mantenido una relación de hecho.

De acuerdo a la última Encuesta Nacional sobre la Dinámica de las Relaciones en los Hogares (ENDIREH, 2016), la violencia familiar ocurrida en los últimos 12 meses, se ha manifestado principalmente en casa de las mujeres y los tipos de violencias más recurrentes son: emocional 59.6 por ciento, económica o patrimonial 17.5 por ciento física 16.9 por ciento y sexual 6.0 por ciento. Los agresores más señalados son los hermanos, el padre y la madre, los principales agresores sexuales son los tíos y los primos. Son datos que constatan lo que ONU mujeres, señaló antes de que existiera COVID-19, la violencia contra las mujeres en el hogar, nos señala el organismo internacional, ya era una de las mayores violaciones de los Derechos Humanos. En los últimos 12 meses, 243 millones de mujeres y niñas (de 15 a 49 años) en todo

suicidio; violencia física, toda acción u omisión intencional que cause un daño a su integridad; violencia sexual, toda acción u omisión que amenaza, pone en riesgo o lesiona la libertad, seguridad integridad y desarrollo psicosexual de la mujer, miradas lasciva, hostigamiento, prácticas sexuales no voluntarias, acoso, violación, explotación sexual comercial, trata de personas para la explotación sexual o el uso denigrante de la imagen de la mujer. Asimismo, en esta Ley se establece en qué ámbitos de la vida están siendo violentadas las mujeres, las define por modalidades: violencia familiar, laboral y docente, comunitaria y violencia institucional, se define también el hostigamiento, acoso sexual y la violencia feminicida, a partir de la cual se tipifica el feminicidio.

2 Por patriarcado entendemos: Un sistema de pactos interclasistas entre varones, una red de fuerzas políticas constituidas por quienes ejercen el poder y se reconocen a sí mismos como sus titulares legítimos. Los iguales existen en tanto tienen algo que repartirse: su dominio y hegemonía sobre las mujeres. Véase Celia Amorós (1994) Feminismo de la Igualdad y diferencia. ( $p$ 23-51) Programa Universitario de Estudios de género UNAM. 
el mundo han sido víctimas de violencia sexual o física por parte de una pareja (CIMAC NOTICIAS, 20 de abril 2020).

En el contexto de pandemia la violencia contra las mujeres en el hogar se manifiesta con intensidad, en el 93 por ciento de mujeres la padecen así lo constata Alanís, (2020) titular de la Comisión Nacional para Prevenir y Erradicar la Violencia contra las Mujeres (Conavim) señala:

En el confinamiento se obliga a las mujeres a estar encerradas con sus agresores. Adicionalmente, al aumentar el tiempo de convivencia se generan conflictos alrededor de cuestiones domésticas y familiares. Agregó, que la situación se agrava porque un número importante de mujeres dependen económicamente de sus parejas, condición que las deja sin la oportunidad de alejarse.

De acuerdo, a la información que proporciona, El Observatorio Ciudadano Nacional del Feminicidio ${ }^{3}$ la violencia sexual, los feminicidios y la desaparición de niñas y adolescentes son hechos que han cobrado importancia en la pandemia, esa organización documento de acuerdo con los datos oficiales del Secretariado Ejecutivo del Sistema Nacional de Seguridad Pública (SESNSP) en el periodo (marzo-julio 2020) los siguientes datos:

- 21,292 delitos sexuales, específicamente 6,440 violaciones sexuales; 8,762 abusos sexuales; 2,189 acosos; 707 hostigamientos sexuales;

- 550 casos de mujeres, niñas y adolescentes desaparecidas, lo que representa el $41 \%$ de las personas desaparecidas a nivel nacional, de acuerdo con el registro de la Comisión Nacional de Búsqueda.

- 90,279 casos de violencia familiar fueron registrados también por el SESNSP.

- EI SESNSP documentó que 1,580 mujeres han sido asesinadas, solo 384 casos se están investigando como feminicidio.

- La Red Nacional de Refugios ha registrado 8,123 llamadas telefónicas y mensajes en redes sociales de personas solicitando apoyo ante situaciones de violencias machistas y ha canalizado a sus 69 espacios de prevención, atención y protección a 15,180 mujeres, niñas y niños víctimas de violencias, lo que representa un incremento del 71 por ciento de personas atendidas en comparación al 2019. ¿frente a estos datos, qué opina el gobierno mexicano, cómo se atiende desde el Estado, la violencia contra las mujeres?

\footnotetext{
${ }^{3}$ El Observatorio Ciudadano Nacional del Feminicidio es una las organizaciones de la sociedad civil más importante en las últimas dos décadas. Ha documentado y acompañado política y legalmente a las madres de las jóvenes desparecidas en el territorio nacional, es una de las organizaciones que defiende los derechos humanos con perspectiva de género y busca contribuir a la garantía del derecho de las mujeres a una vida libre de violencia, al acceso a la justicia y erradicación de la violencia de género, los feminicidios y la discriminación contra las mujeres. Se haya conformado por 40 organizaciones de 22 estados del país, que defienden los derechos de las mujeres.
} 


\section{El Gobierno tiene otros datos: impunidad y omisión}

Ante los datos que refieren las organizaciones de la sociedad civil feministas, el presidente López Obrador, el 6 de mayo del 2020, durante la conferencia matutina señalo que no ha habido un incremento en el número de denuncias, que "no aplica" en México medir con los mismos parámetros internacionales la violencia familiar y que lo que hay en las familias durante el confinamiento es "fraternidad."

Sus decisiones y omisiones fortalecen la impunidad y normalizan la violencia contra las mujeres, niñas y niños al negar e ignorar el peligro que viven las mujeres en sus hogares, desde su visión autoritaria y misógina, los conflictos familiares se resuelven mostrando la "banderita blanca" de paz y armonía en la comunicación familiar, nada más lejano, de lo que realmente sucede en las familias mexicanas. El presidente de México, en sus dos años de gobierno, no ha enviado ninguna señal política y ética que muestre su interés en atender de manera contundente la violencia contra las mujeres en nuestro país. Es evidente que en la clase política de este gobierno, hay discursos contradictorios, ponemos un ejemplo: el 25 de noviembre, día internacional de la no violencia contra las mujeres, el presidente de la republica de nueva cuenta insistió que la violencia familiar es consecuencia de la pérdida de valores (sic) y la desintegración familiar, consecuencia del neoliberalismo; en contraste, la Secretaría de Gobernación, Olga Sánchez Cordero, refiere al sistema patriarcal y al machismo, como causas de la violencia y exhorta a tener claro que no es lo mismo feminicidio y homicidio. Quizá la visión de la secretaria de estado sea más cercana a lo que sucede, pero su actuación frente a los hechos ha sido tibia y poco eficaz, los reclamos de la sociedad civil organizada, de las madres que buscan a sus hijas desaparecidas, de las marchas multitudinarias, de las mujeres que solicitan refugios y ordenes de contención nos muestran otros contextos. De ahí que uno de los movimientos más transgresores y desafiantes al gobierno que encabeza Andrés Manuel López Obrador, sea justamente el movimiento feminista. 
La Voz y lucha de las organizaciones Feministas ${ }^{4}$

El movimiento social feminista en estos meses de encierro ha documentado y denunciado que en las instituciones de seguridad y procuración de justicia sigue predominando una situación de impunidad, que ha llevado a México a ocupar el 4일 lugar de 13 países con altos niveles de impunidad. El miedo a las amenazas de los agresores y el desconocimiento de mecanismos de justicia contribuye a que sólo $10 \%$ de mujeres denuncie los hechos de violencia, lo que incide en el incremento de feminicidios. De igual forma, no hay voluntad política para impulsar la tipificación de delitos como el feminicidio; existe una falta de armonización legislativa con los estándares internacionales; se adolece de protocolos de investigación especializados en violencia de género; los impartidores de justicia no están capacitados para atender asuntos de derechos humanos y género; hay carencia de políticas públicas con perspectiva de género. Todos estos aspectos en conjunto, son factores que impiden actualmente el acceso de las mujeres a la justicia, a lo que se suma la falta de diligencia por parte de las autoridades encargadas de investigar, sancionar y reparar a las víctimas, que lejos de favorecer la prevención y erradicación de las violencias contra las mujeres ha llevado a una situación intolerable de impunidad. Estrada (septiembre 2020)

\section{Violencia Extrema: Feminicidio en México}

El pasado 8 de marzo, la ciudad de México fue un escenario que evidencio el hartazgo, indignación y exigencia de derechos humanos, frente a la expresión extrema de la violencia

\footnotetext{
${ }^{4}$ Las organizaciones de la sociedad civil feministas son amplias, diversas y heterogéneas (Equis Justicia, Apis Fundación la Equidad, Red Nacional de Refugios, Línea Violeta, Red de contención emocional de la colectiva feminista las Brujas del mar, Observatorio Ciudadano Nacional del feminicidio) en los meses de pandemia han cerrado filas en contra de la violencia hacia las mujeres. Se han organizado no solo para denunciar lo que sucede en el ámbito de lo privado, además han impulsado un trabajo intenso para romper, destrabar esa idea dominante de la "naturalización" "normalización de la violencia", al tiempo que han tejido lazos soricos de atención y ayuda a mujeres e hijos-hijas que lo necesitan, han fortalecido en la conciencia de las mujeres la idea de la cultura de la denuncia, mostrándoles que tienen el derecho humano a no ser violentadas. La campaña intensa que entorno al 25 de noviembre día internacional de la no violencia contra la mujer fue: \# Nos van a ver juntas! ésta intenta deja claro en el imaginario de las mujeres, que frente a la violencia iNo estás sola!
} 
contra la mujer, el Feminicidio. Miles de mujeres jóvenes, adultas, citadinas, indígenas, trabajadoras, estudiantes, marchamos para exigir "Ya basta", "Ni una más," fue un clamor nacional e internacional en nuestro continente.

La problemática de la violencia contra las mujeres, en especial del feminicidio, ha causado preocupación en la sociedad mexicana, ha provocado el interés académico, periodístico y jurídico y ha llamado la atención de diversos organismos nacionales e internacionales de derechos humanos, que se han dado a la tarea de investigar y documentar esta situación.

El discernimiento de lo que ha sido el feminicidio, ha significado un proceso largo, la documentación hemerográfica, el acompañamiento y documentación de casos; la denuncia y movilización de las madres de las víctimas, acompañadas por las organizaciones de la sociedad civil, que ante la negligencia y desinterés de los distintos gobiernos de México, colocaron la problemática a nivel internacional, lo cual favoreció a que los organismos internacionales de derechos humanos comenzaran a mirar y atender esta problemática en México. (OCNF, 25 mayo 2020)

Diana Russell, utilizó el término femicide por primera vez en 1976 ante el Tribunal Internacional sobre los Crímenes contra la Mujer en Bruselas, para definir las formas de violencia extrema contra la mujer. La misma Russell, junto con Jane Capputi, redefine este concepto en 1990 como "el asesinato de mujeres por hombres motivado por el odio, desprecio, placer o sentido de posesión hacia las mujeres" (RUSSELL, 1977) El feminicidio es el asesinato de una mujer por el simple hecho de serlo, es decir, un asesinato misógino de mujeres por hombres. Investigadoras feministas mexicanas como Marcela Lagarde y Julia Monárrez (1999) retomaron el concepto de Diana Russell, pero coincidieron en que el feminicidio en México reflejaba, además, el elemento de impunidad del Estado como una forma de permisividad ante la omisión de dichos crímenes, lo cual agravaba la problemática.

El feminicidio a lo largo de este confinamiento se ha incrementado en el periodo (marzo-octubre 2020) los datos nos muestran existe un aumento de $2.79 \%$ con respecto al 2019. De acuerdo a las cifras del Secretariado Ejecutivo del Sistema Nacional de Seguridad Pública, se documentaron 777 presuntos delitos de feminicidio. El Estado de México representa el primer lugar con 119 víctimas, seguido de Veracruz con 71 el tercer lugar lo representa 
la Ciudad de México con 61 víctimas. Del mismo modo los municipios con más presuntos delitos de feminicidios son: Juárez-Chihuahua con 19 casos, Tijuana-Baja California con 17 casos, Monterrey-Nuevo León con 15 casos, Culiacán-Sinaloa con 12 casos.

En el contexto de pandemia, la procuración de justicia se ha aletargado, las fiscalías y los tribunales estatales se han visto superadas por la demanda, la disminución de personal, los horarios restringidos han constituido barreras para el acceso a la justicia, no obstante las organizaciones de la sociedad civil han generado estrategias de apoyo, atención, han impulsado campañas de ayuda, \#Distancia segura y sin violencias, infografías en las que se expone qué son las órdenes de protección, ante quién se solicitan, información valiosa para aquellas mujeres que han decidido parar la violencia en sus vidas.

La violencia en las universidades

Las instituciones educativas no están exentas de padecer violencias. En la Instituciones de Educación Superior éstas se ejercen mediante conductas verbales y/o físicas relacionadas con la sexualidad, son de connotación lasciva, se llevan a cabo sin el consentimiento del receptor, y se manifiestan por medio del acoso y hostigamiento sexual. La diferencia radica en que el acoso se da entre compañeros o desconocidos, y en el hostigamiento el acosador posee una posición jerárquica mayor que la víctima. El hostigamiento y acoso sexual no es exclusivo de un género, pero sí es padecido mayoritariamente por mujeres, seguido por otras identidades y orientaciones sexuales que no se rigen por estándares del poder hegemónico masculino y heterosexual. (CORDOVA Y NUNEZ, 2019) Al Respecto, el Instituto Nacional de la Mujeres (2016) nos señala: "Las mujeres sufren de hostigamiento sexual (manoseo, exhibicionismo e intento de violación) y violación, son delitos perpetrados en su mayoría por hombres (99.6\%) y ocurren principalmente en la calle $(59.0 \%)$ y en el transporte público (20.4\%)".

En las universidades públicas y privadas las jóvenes universitarias han emprendido un movimiento social feminista que vincula el entronque entre capitalismo y patriarcado y en éste se expresa una crítica contundente al carácter violento de una realidad política cultural y social, hetero normada, machista y sexista.

este feminismo diverso, está conformado por una multiplicidad de organizaciones y colectivos que irrumpen en el espacio público con una reflexión que tematiza y visibiliza nuevamente la construcción patriarcal en la que vivimos. Dan cuenta de las incongruencias, explotaciones, prejuicios y violencia que, 
si bien se representan de forma categórica y explicita en las mujeres, en algunos casos incluyen en su discurso las luchas de la disidencia sexual e incluso la incorporación de hombres heterosexuales en el movimiento" (LUNA, 2019 p. 284).

El movimiento feminista estudiantil, fue contundente al marcar al acoso y hostigamiento sexual como un asunto no privado, más bien se ha convertido, en un gran tema público-político, lo que se hizo evidente con el movimiento \#Me too ${ }^{5}$, los tendederos en las universidades y la toma de instalaciones por las jóvenes estudiantas en la Instituciones Educación Superior. El escracheo ${ }^{6}$ en las universidades para denunciar el acoso y hostigamiento sexual que experimentan, junto con la creciente movilización de jóvenes obligo a diversos actores de las instituciones educativas a atender las demandas de launiversitarias.

Actualmente diversas universidades (Universidad Nacional Autónoma de México, Universidad Autónoma Metropolitana, Instituto Politécnico Nacional, Universidad Iberoamericana) en el país, están implementando acciones al respecto, han creado protocolos de seguridad que atienden los casos que se presentan dentro de sus espacios, no obstante, no es suficiente se requieren cambios en la cultura institucional, impulsar programas educativos que transversalicen los estudios críticos de género en los planes y programas de estudio, fortalecer una política institucional de igualdad en las instituciones de educación superior, impulsar códigos de ética que alimenten las relaciones de respeto, no sexistas o misóginas entre el estudiantado y el profesorado, el trabajo institucional apenas empieza.

\footnotetext{
${ }^{5}$ \# Me Too fue un Movimiento popularizado en 2017. Iniciado por la activista social Tarana Burke39 para denunciar acoso sexual, se difundió debido a la denuncia en contra del productor de cine norteamericano Harvey Weinstein. En 2018 en México tuvo un impacto mediático a partir de las denuncias realizadas por figuras públicas y actrices, lo cual derivó en una intensa discusión sobre la violencia sexual que asola al país.

${ }^{6}$ En la UNAM, en mayo de 2015, un profesor del Colegio de Ciencias y Humanidades Plantel Vallejo fue condenado a nueve meses de prisión por el delito de abuso sexual agravado. En mayo de 2016, una estudiante hizo pública su denuncia luego de sufrir abuso sexual por parte de un sujeto desconocido en los baños de la Facultad de Ciencias Políticas y Sociales. En abril de 2017, el catedrático y conductor de Radio UNAM, Marcelino Perelló Valls, fue despedido de la máxima casa de estudios por acusaciones de abuso sexual y comentarios misóginos emitidos en su programa de radio.
} 
Los contextos de encierro que impuso la contingencia, no han impedido que las jóvenes continúen virtualmente en su movilización. Se apropiaron del espacio digital y han visibilizado sus demandas en el mundo, las redes internacionales de encuentro ${ }^{7}$ del movimiento feminista que encabezan las jóvenes, han sido posibles por la cercanía digital que visibiliza la defensa de los derechos de las mujeres. El feminismo de la cuarta ola, que hoy prevalece en el continente latinoamericano está definido por la tecnología, internet lo que ha propiciado construir un movimiento on line fuerte, popular y reactivo. El ciberactivismo es una marca de la $4^{\circ}$ ola feminista. Las jóvenes universitarias, se articulan alrededor de la denuncia contra la violencia sexual, el patriarcado y la misógina que domina en los salones de clase, en los órganos de gobierno, en los espacios donde se toman las decisiones. Las jóvenes ya no están dispuestas a callar, a someterse, están organizadas y se revelan. Su transgresión, rebeldía y propuesta apunta a la configuración de formas diferentes de ser y estar en el mundo.

Valdría la pena caer en cuenta de que las mujeres han creado una composición compleja que emite fuerza, supone coraje y contiende por la NO VIOLENCIA. El movimiento del 8 de marzo del 2020, sin duda fue un momento emblemático para feministas y no feministas, la idea de crear alianzas entre mujeres, dando cabida a la generación de acuerdos, proponiendo diálogos sobre temáticas nunca antes abordadas y generando posibles agrupaciones de mujeres que aboguen por sí mismas y por muchas más ha sido una experiencia ejemplar, las mujeres, pintaron el centro de la Ciudad de México con colores icónicos, representativos y esperanzadores: morado y verde.

\section{Reflexiones finales}

La pandemia Covid-19 ha impuesto en nuestras vidas un panorama incierto, en la salud de las personas, la vacuna abre nuevas esperanzas, pero no conocemos cabalmente, cuáles serán sus resultados, mientras tanto, los contagios se recrudecen y el número de falle-

\footnotetext{
${ }^{7}$ La Cuarta revolución industrial, de acuerdo a Klaus Schwab fundador del Foro Económico Mundial, está cambiando la forma de vivir, trabajar t relacionarnos. Se basa en el exponencial y vertiginoso desarrollo tecnológico desde campos de inteligencia artificia, robótica, el internet de las cosas, la impresión 3 D. nanotecnología, biotecnología computación cuántica. Véase Feminismo 4. Nuria Varela. Asistimos entonces a lo que se conoce la nueva era del capitalismo. Capitalismo digital Esto confirma que, en el capitalismo, después de la era del carbón y del acero, la del ferrocarril y la electricidad, y la del petróleo, llega la hora de los datos, la nueva materia prima dominante en la era postpandémica. Bienvenidos al capitalismo digital
} 
cidos en este inicio de año 2021 se agudiza; la cesantía se incrementa tras las medidas sanitarias de salud que imponen los gobiernos, y la pobreza y desigualdad cobra sus expresiones mas contundentes. Hoy es más común tener algún familiar, amigo o conocido contagiado por el virus y lo más lamentable, en muchos persiste el dolor por la pérdida de algún ser querido. Conmovedoramente fuerte, ha sido la experiencia vital, que la Covid ha impuesto en nuestras vidas.

Un hecho social indiscutible, es el predominio de la violencia sexual y familiar contra las mujeres en tiempos de Covid. En este artículo, mostramos los datos de una de las pandemias que ha estado presente en cientos de mujeres mexicanas, la violencia contra las mujeres, el encierro la ha agudizado. Ante ésta, se activado, adquirido una gran fuerza sociopolítica el movimiento feminista, uno de los movimientos sociales más desafiantes, críticos y transgresores de la cultura patriarcal. Al tiempo que también se constituye en un movimiento social propositivo ante las desigualdades de género, ha impulsado un trabajo intenso para romper, destrabar esa idea dominante de la "naturalización" normalización de la violencia contra las mujeres, ha tejido lazos soricos de atención y ayuda a mujeres e hijas-hijos que lo necesitan, fortaleciendo en la conciencia de las mujeres, la idea de la cultura de la denuncia, mostrándoles que son sujetas de derechos y que la violencia que padecen, es una manifestación de violación a sus derechos humanos.

El movimiento feminista estudiantil, protagonizado principalmente por mujeres jóvenes, ha puesto en la escena publica los asuntos que por mucho tiempo se consideraron privados, ha expresado como la práctica del acoso y hostigamiento sexual dejo de ser un asunto privado y se ha convertido en un gran tema público-político, que ha obligado a las instituciones de educación superior a tomar medidas para su atención.

Por su parte, en la violencia doméstica, sexual y el feminicidio el gobierno mexicano ha sido omiso en atenderlas. Las mujeres han encontrado respuesta y atención en la sociedad civil organizada de mujeres feministas, que no solo dan otros datos frente a lo que expone el presidente, sino además visibilizan el problema, exigen derechos para las víctimas, promueven órdenes de protección y acompañan a las mujeres jurídica y psicológicamente.

La violencia requiere transformar las relaciones entre los sexos, lo cual implica también, transformar la política sexual y con ello el sistema patriarcal que la ha establecido. 


\section{REFERENCIAS BIBLIOGRÁFICAS}

AMORÓS, Celia. Feminismo de la Igualdad y diferencia. Programa Universitario de Estudios de género. México: UNAM, 1994.

ALANIS, Fabiola. Entrevista en https://www.eluniversal.com.mx/nacion/en-el-hogar-93-de-ataquesmujeres-por-covid-19 (20/12 2020)

BYUNG, Chul Han. El Enjambre. México: Herder, 2016.

CATAÑEDA, Martha Patricia. Metodología de la Investigación Feminista. México: Centro de Investigaciones Interdisciplinarias en Ciencias y Humanidades CEIIHC Universidad Nacional Autónoma, 2008.

CIMAC- Noticias Periodismo con Perspectiva de Género, https://cimacnoticias.com.mx/2020/12/03/estado-de-mexico-rezagado-en-justicia-para-las-mujeres-porpandemia.

CORDOVA, Carolina Núñez, Vanessa Hostigamiento y Acoso Sexual en las Universidades. Caso de Estudio UAM Cuajimalpa. México: UAM Cuajimalpa, Idónea Comunicación de Resultados para obtener el grado de: Maestro/a en Diseño, Información y Comunicación 2019.

ESTRADA, Luz Coordinadora General del Observatorio Ciudadano Nacional del Feminicidio. México https://www.observatoriofeminicidiomexico.org/.

ENCUESTA Nacional Sobre la Dinámica de Relaciones en los Hogares (2016). México: Instituto Nacional Instituto Nacional de Estadística y Geografía,2016.

FOLLEGATI, Luna El feminismo se ha vuelto una necesidad: movimiento estudiantil y organización feminista (2000-2017) en Revista Anales No. 14, Universidad de Chile. Recuperado de: https://anales.uchile.cl/index.php/ANUC/article/view/51156, 2018.

LEY General de Acceso a una vida Libre de Violencia Instituto Nacional de las Mujeres, México: INMUJERES 2007.

OBSERVATORIO Ciudadano Nacional del Feminicidio, Recuperado de: https://www.observatoriofeminicidiomexico.org/, 25 de noviembre 2020.

ONU MUJERES, 6 abril de 2020. Recuperado de: https://www.unwomen.org/es/news/stories/2020/11/compilation-take-action-to-help-end-violence-against-women.

OXFAM, Combatir la desigualdad en tiempos del coronavirus: Índice de Compromiso con la Reducción de la Desigualdad. Acceso em: https://oxfamilibrary.openrepository.com/bitstream/handle/10546/621061/rr-fighting-inequality-covid-19-cri-index-081020-es.pdf. Recuperado 2020.

RAMONET, Ignacio. La pandemia y el sistema-mundo. https://www.nodal.am/2020/04/la-pandemiay-el-sistema-mundo-por-ignacio-ramonet.

RUSSELL,Diana y Harmes, Roberta Feminicidio: una perspectiva global, México: Centro de Investigaciones Interdisciplinarias en Ciencias y Humanidades, CEIICH UNAM, 2010. 